Addendum

\title{
Tanabe, K. A Review of Ultrahigh Efficiency III-V Semiconductor Compound Solar Cells: Multijunction Tandem, Lower Dimensional, Photonic Up/Down Conversion and Plasmonic Nanometallic Structures. Energies, 2009, 2, 504-530.
}

\author{
Katsuaki Tanabe ${ }^{1,2}$ \\ 1 Institute of Industrial Science, University of Tokyo, Tokyo 153-8505, Japan; \\ E-Mail: tanabe@iis.u-tokyo.ac.jp \\ 2 Institute for Nano Quantum Information Electronics, University of Tokyo, Tokyo 153-8505, Japan
}

Received: 25 August 2009 / Accepted: 26 August 2009 / Published: 26 August 2009

I have stated in my recent review article [1] that no direct observation of multiple exciton generation (MEG) in the shape of photocurrent extracted from a semiconductor had been made yet. However, there have been indeed a couple of reports on the photocurrent measurements for colloidal II-VI semiconductor compound quantum dot (QD) and polymer-QD composite solar cells and photodetectors to indicate MEG in the QDs, including demonstrations of over-100\% external quantum efficiencies [2-4]. Particularly, Sukhovatkin et al. have presented a universal spectral quantum efficiency enhancement curve dependent only on bandgap-normalized photon energy consistent among photodetectors with varied PbS QD bandgap energies as a signature of MEG, eliminating potential artifactual explanations for the observed photocurrent enhancement represented by external trap states induced absorption or transitions [5].

\section{References and Notes}

1. Tanabe, K. A review of ultrahigh efficiency III-V semiconductor compound solar cells: multijunction tandem, lower dimensional, photonic up/down conversion and plasmonic nanometallic structures. Energies 2009, 2, 504-530.

2. Qi, D.; Fischbein, M.; Drndic, M.; Selmic, S. Efficient polymer-nanocrystal quantum-dot photodetectors. Appl. Phys. Lett. 2005, 86, 093103.

3. Kim, S.J.; Kim, W.J.; Sahoo, Y.; Cartwright, A.N.; Prasad, P.N. Multiple exciton generation and electrical extraction from a PbSe quantum dot photodetector. Appl. Phys. Lett. 2008, 92, 031107.

4. Kim, S.J.; Kim, W.J.; Cartwright, A.N.; Prasad, P.N. Carrier multiplication in a PbSe nanocrystal and P3HT/PCBM tandem cell. Appl. Phys. Lett. 2008, 92, 191107. 
5. Sukhovatkin, V.; Hinds, S.; Brzozowski, L.; Sargent, E.H. Colloidal quantum-dot photodetectors exploiting multiexciton generation. Science 2009, 324, 1542-1544.

(C) 2009 by the authors; licensee Molecular Diversity Preservation International, Basel, Switzerland. This article is an open-access article distributed under the terms and conditions of the Creative Commons Attribution license (http://creativecommons.org/licenses/by/3.0/). 